RESEÑA

\title{
DÍAZ, Claudio Choco (2020). Democracia y Derecho Internacional: ¿una nueva relación? Rosario: Laborde Editor. 132 páginas
}

Como señala el Prof. Claudio Choco Díaz en su libro Democracia y Derecho Internacional: ¿Una nueva relación?, aunque es arriesgado concluir que existe un principio democrático de carácter universal, sí se puede afirmar que dicho principio se está gestando en la vida política y jurídica americana (p. 121). En nuestra región, la ruptura del orden democrático en un determinado Estado, es decir, una sucesión de gobiernos que violente los preceptos constitucionales ha dejado de ser un asunto que pertenece estrictamente a su dominio reservado para pasar a estar regulado por el derecho internacional americano.

Los países de nuestro continente, particularmente los de Centroamérica, el Caribe y América del Sur, han sufrido, históricamente, interrupciones de sus procesos democráticos con el surgimiento de gobiernos de facto, amparados en un pétreo principio de no intervención en los asuntos internos de los Estados. Frente a esta realidad política y social, ya desde los primeros años del siglo XX, comienza a surgir una serie de doctrinas que colocan en tensión el mencionado principio de no intervención, por una parte, con aquél que promueve la defensa de la democracia, por otra. Se trata de las denominadas doctrinas o teorías del "desconocimiento" que proponen, en línea general, no reconocer a los gobiernos implantados al margen de los mecanismos de acuerdo a los cuales se realizan los cambios en el ejercicio del poder en un Estado determinado (p. 15). El abordaje de estas doctrinas constituye el punto de partida del estudio al que se dedica esta obra.

El objetivo declarado por el autor es, a lo largo de los siete capítulos del trabajo, “analizar las teorías del 'desconocimiento' como un primer paso en el desarrollo que concluirá en la incorporación de cláusulas democráticas en los tratados internacionales de la región" (p. 11). En este proceso, no obstante, habrá que esperar hasta la década de 1990 para que las ya existentes disposiciones convencionales relativas a la defensa de la democracia adquieran verdadera eficacia. Esto fue posible dado que es en esta década cuando confluyen dos cambios fundamentales: por una parte, en el ámbito latinoamericano, se habían iniciado en la década de 1980 los procesos de transición democrática y, por otra, a nivel internacional, se observa un verdadero cambio sistémico con la disolución del bloque soviético y el consecuente fin de la Guerra Fría que elimina para los Estados Unidos el argumento de sostener cualquier gobierno en la región que constituyera una garantía para evitar el avance comunista en el continente, independientemente de que éste fuera de jure o de facto.

A partir de estos cambios, se inicia un período especialmente fructífero en la evolución ya que cobran cada vez más fuerza "las ideas que sostienen que la instalación de un gobierno de facto no es sólo un problema interno sino que constituye, a la luz de posiciones doctrinarias, tratados internacionales y acciones concretas de actores internacionales, una cuestión que excede este ámbito nacional para ser parte de la agenda internacional" (p. 19). 
En este proceso de afirmación de la defensa de los valores democráticos se observan, en primer lugar, los avances operados en la Organización de Estados Americanos (OEA), con la aprobación, entre otros documentos, de la Resolución 1080 (Democracia Representativa), en 1991, y la Carta Democrática Interamericana, en 2001. Esta última vincula la democracia no sólo con el fortalecimiento y la preservación de la institucionalidad democrática, sino también con los Derechos Humanos, el desarrollo integral y el combate a la pobreza, las misiones de observación electoral, y la promoción de la cultura democrática (p. 60).

Paralelamente, en la subregión del Cono Sur, "los nuevos gobiernos democráticos buscaron consolidar sus propias democracias apoyados en la integración con sus vecinos" (p. 77). En este contexto surge el MERCOSUR con la firma del Tratado de Asunción en marzo de 1991, entre Argentina, Brasil, Paraguay y Uruguay. Si bien con objetivos económicos y comerciales, se destacan los valores compartidos como, en particular, el compromiso con el fortalecimiento de la democracia, que va a cimentar a lo largo de la década de 1990 el desarrollo posterior en la materia plasmado en declaraciones y protocolos que reflejan la voluntad de los Estados Partes (más Bolivia y Chile).

A modo de evidenciar la aplicación efectiva de los desarrollos axiológicos y normativos en esta nueva etapa, el autor dedica el capítulo VI al análisis del intento de golpe de Estado al presidente de Paraguay, Juan Carlos Wasmosy, en el año 1996. Esta crisis se resolvió satisfactoriamente no sólo por la reacción de la sociedad paraguaya sino, además, por la decidida presión internacional ejercida por el MERCOSUR y la OEA, incluso antes de que se firmaran (y sin dudas como antecedente de), respectivamente, el Protocolo de Ushuaia (1998) y la Carta Democrática Interamericana (2001).

En el capítulo final, el autor aborda la constitución y la labor de la Unión de Naciones Suramericanas (UNASUR), a la que califica como "un intento en el camino". Esta organización, surgida en 2008 "como consecuencia de las coincidencias políticas de varios jefes de Estado con fuerte relevancia en la región en aquel momento" (p. 115), no realizó un gran aporte en tanto proceso de integración en sí, pero resultó notable su accionar para la preservación de la democracia a través de la solución institucional de las crisis de Bolivia (2008), Honduras (2009) y Ecuador (2010).

Es innegable el significado de estos avances y experiencias, como se remarca en distintos puntos de la obra. No obstante, resta todavía el desafío, para los países de la región, de superar la denominada "dimensión minimalista" de la democracia (p. 15), limitada casi exclusivamente al respeto de los procesos electorales como medio de sucesión de los distintos gobiernos. A fin de lograr (o por lo menos tender a) este objetivo resulta imperioso, por una parte, mejorar la calidad de las instituciones democráticas y, por otra, avanzar hacia un "concepto integral de democracia" (p. 65), vinculada con la vigencia y el respecto de los Derechos Humanos, el desarrollo regional y el combate de la pobreza en el continente.

Esta obra, escrita con rigurosidad académica y a la vez claridad expositiva, constituye un importante aporte al estudio de la temática, al abordar de manera integral el estudio de la génesis y evolución posterior del principio democrático en nuestro 
continente, y al dejar planteadas algunas reflexiones e interrogantes en cuanto al futuro de las democracias americanas.

Por Lidia Gatti. Magister en Integración y Cooperación Internacional (CERIR-CEIUNR). Docente de la cátedra Derecho Internacional Público, Facultad de Ciencia Política y Relaciones Internacionales, Universidad Nacional de Rosario (UNR, Argentina). Correo electrónico: lidiavgatti@hotmail.com. ORCID: 0000-0002-2600$307 \mathrm{X}$. 